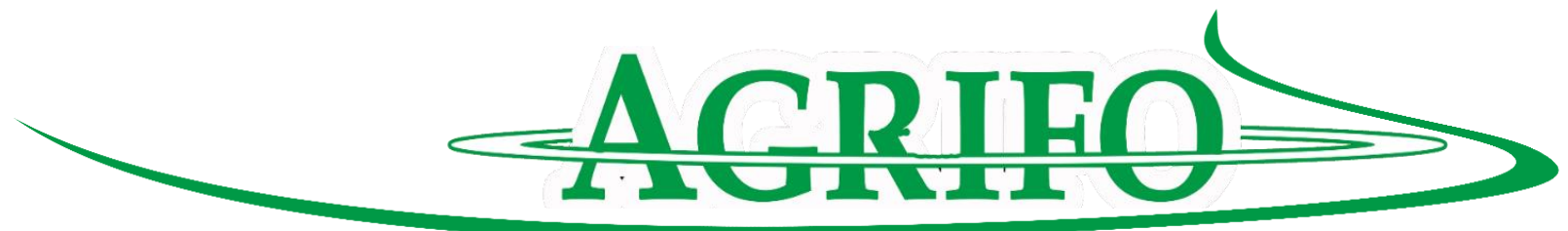

\title{
ANALISIS DAMPAK REHABILITASI JARINGAN IRIGASI TERSIER TERHADAP PENDAPATAN PETANI DI KABUPATEN ACEH BESAR
}

\section{Evariani $^{1}$}

Corresponding Author : evarianijabbar@gmail.com

\section{ABSTRACT}

The function of the irrigation is very important in agriculture system. Irrigation is utilized by farmers particularly rice farmers to irrigate and maintain the adequacy of water in their rice fields. Since the first of the irrigation system has developed, the different in quality and system managements still, Aceh Besar regency has an area of 31,998.0 Ha of rice fields and the land that have irrigation scope are 20,275 Ha. With the irrigation rehabilitation programs becoming more eficient in rice production and farmer's income are increasing therefore the researce on the analysis of impact the rehabilitation of tertier irrigation on farmer's income and an analysis of the breakeven point (BEP) in Aceh Besar regency conducted. This research was conducted with a purposive sampling method (deliberately) based on the consideration of farmers around the location of the study received support rehabilitation of irrigation tertiary fund budget for fiscal year 2016 for data analysis using quantitative approaches such as analysis of t test, $\mathrm{R} / \mathrm{C}$ ratio and analysis of breakeven point.

Keywords: Rice farming, rehabilitation, tertiary irrigation, rice production, farmer's income.

\section{PENDAHULUAN}

Kegiatan Usahatani padi yang bertujuan agar terpenuhinya kebutuhan pangan masyarakat diharapkan juga dapat meningkatkan kesejahteraan para petaninya. Maka sampai sekarang bidang pertanian masih menjadi bidang yang sangat diperhitungkan dan bidang ini masih merupakan sumber pemenuhan pangan utama bagi penduduk Indonesia. Beras merupakan bahan pangan pokok sebagian besar masyarakat Indonesia. Untuk meningkatkan produksi beras ada beberapa hal yang dapat dilakukan salah satunya adalah penyediaan sarana pengairan (pembangunan dan rehabilitasi jaringan irigasi) yang baik dan cukup (Simatupang \& Rusastra, 2004).

Pengelolaan infrastruktur irigasi yang baik sangat penting agar dapat tercapainya multifungsi di bidang pertanian. Pasandaran (2016) Fungsi dari irigasi sangat penting yaitu sebagai sarana untuk mencukupi ketersedian air untuk usahatani padi sawah.

Kabupaten Aceh Besar memiliki luas lahan sawah 31.998,0 Ha dan lahan yang memiliki irigasi berjumlah 20.275 Ha. Jumlah yang irigasi yang tersedia masih kurang untuk memenuhi ketersediaan air untuk usahatani padi. Apalagi dengan semakin lamanya umur jaringan irigasi, maka sarana penunjang pertanian ini akan mengalami kerusakan baik kerusakan ringan maupun kerusakan berat yang dapat menganggu atau mengurangi fungsi dan kegunaannya sebagaimana yang diharapkan yang bertujuan untuk peningkatan produksi dan pendapatan petani, maka perlu adanya kegiatan rehabilitasi pada jaringan irigasi terutama jaringan irigasi tersier yang

\footnotetext{
${ }^{1}$ Mahasiswa Magister Agribisnis Universitas Syiah Kuala
} 
berhubungan langsung dengan lahan petani.

Tujuan dari penelitian ini adalah : (1) Dampak rehabilitasi jaringan irigasi tersier terhadap pola tanam, produksi padi sawah dan pendapatan petani di Kabupaten Aceh Besar.(2) Untuk mengetahui tingkat break event point (BEP) dari kegiatan rehabilitasi jaringan irigasi tersier.

\section{METODE PENELITIAN}

Lokasi penelitian adalah wilayah pertanian padi pada lahan sawah irigasi di Kecamatan Ingin Jaya, Krueng Barona Jaya, Kuta Baro, Suka Makmur, Montasik, Indrapuri dan Kuta Cot Glie Kabupaten Aceh Besar yang jaringan irigasi tersiernya telah direhabilitasi pada tahun 2016.
Data yang diperoleh dalam penelitian ini adalah data primer dan data sekunder. Data primer diperoleh melalui pengamatan langsung kelapangan dan dengan teknik wawancara individu melalui pengisian kuesioner terstruktur terhadap 82 petani responden. Pengumpulan data usahatani dilaksanakan secara simultan sebelum rehabilitasi (tahun 2015) dan sesudah rehabilitasi jaringan irigasi (tahun 2017). Data yang dikumpulkan meliputi jenis pola tanam usahatani padi, produksi padi dan tingkat pendapatan petani dalam usahatani padi sawah sebelum dan sesudah rehabilitasi jaringan irigasi.

Penelitian ini merupakan penelitian kualitatif dan kuantitatif karena data yang digunakan berbentuk narasi dan angka yang selanjutnya akan diolah untuk mengetahui pengaruh dari masingmasing variabel yaitu:

\section{Analisis Pola Tanam}

Tabel 1. Tabulasi Ketersediaan Air Irigasi Terhadap Pola Tanam

\begin{tabular}{lll}
\hline No & Ketersediaan air untuk jaringan irigasi & Pola tanam dalam satu tahun \\
\hline 1. & Tersedia air cukup banyak & $\begin{array}{l}\text { Padi-Padi-Padi } \\
\text { Padi-Padi-Palawija }\end{array}$ \\
\hline 2. & Tersedia air dalam jumlah cukup & $\begin{array}{l}\text { Padi-Padi-Bero } \\
\text { Padi-Palawija-Palawija }\end{array}$ \\
\hline 3. & Daerah yang cenderung kekurangan air & $\begin{array}{l}\text { Padi-Palawija-Bero } \\
\text { Palawija-Padi-Bero }\end{array}$ \\
\hline
\end{tabular}

Sumber : Sidharta, 1997

\section{Analisis Produksi Padi dan Pendapatan Petani}

Untuk mengetahui perbedaan pendapatan petani sebelum dan sesudah rehabilitasi digunakan uji $\mathrm{t}$ sebagai berikut :

$$
t_{\text {cari }} \frac{\overline{\mathrm{X}}_{1}-\overline{\mathrm{X}}_{2}}{\operatorname{Sp} \sqrt{\left(\frac{1}{n_{1}}+\frac{1}{n_{2}}\right)}}
$$

Dimana:

$\overline{X_{1}}=$ Rata-rata pendapatan sesudah rehabilitasi

$\bar{X}_{2} \quad=$ Rata-rata pendapatan sebelum rehabilitasi

$n_{1}=$ Jumlah sampel sesudah rehabilitasi

$n_{2} \quad=$ Jumlah sampel sebelum rehabilitasi 
$S p=$ Varian proporsional dari pendapatan petani sebelum dan sesudah rehabilitasi

Varians dihitung dengan menggunakan rumus:

$S_{1}^{2}=\frac{\sum X_{i .1}^{2}-\left(\frac{x_{1.1}}{n_{1}}\right)^{2}}{n-1}$

$S_{2}^{2}=\frac{\sum X_{i .2}^{2}-\left(\frac{x_{1.2}}{n 2}\right)^{2}}{n-1}$

Varian proporsional dari pendapatan petani sebelum dan sesudah rehabilitasi dihitung menggunakan rumus:

$$
S p=\sqrt{\frac{\left(n_{1}-1\right) S_{1}^{2}+\left(n_{2}-1\right) S_{2}^{2}}{n_{1}+n_{2}-2}}
$$

Dengan kaidah pengambilan keputusan melalui metode analisis sebagai berikut:

- Jika $t_{\text {cari }}>t_{\text {tabel, }}$, maka menerima Ha dan menolak Ho

- Jika $t_{\text {cari }} \leq t_{\text {tabel, }}$, maka menolak Ha dan menerima Ho

Pengujian Hipotesis dapat diuraikan sebagai berikut:

$\mathrm{H}_{0}$ : Pendapatan dan produksi usahatani padi tidak berpengaruh positif dengan adanya rehabilitasi jaringan irigasi tersier.

$\mathrm{H}_{\mathrm{a}}$ : Pendapatan dan produksi usahatani padi berpengaruh positif dengan adanya rehabilitasi jaringan irigasi tersier.

Untuk mengetahui suatu usahatani menguntungkan atau tidak, digunakan analisis $R / C$ ratio.
$\mathrm{R} / \mathrm{C}=\frac{\text { Total Penerimaan }}{\text { Total Biaya }}$

Kriteria pengambilan keputusan

- Jika R/C> 1, maka usahatani mengalami keuntungan karena penerimaan lebih besar daripada pengeluaran.

- Jika R/C < 1, maka usahatani mengalami kerugian karena penerimaan lebih kecil daripada pengeluaran.

- Jika $\mathrm{R} / \mathrm{C}=1$, maka usahatani tersebut dalam keadaan break even point (impas), karena besarnya penerimaan sama dengan besarnya pengeluaran.

\section{Break Even Point}

BEP digunakan untuk mengetahui waktu kembalinya modal dari rehabilitsai jaringan irigasi tersier (Suharto, Wirosoedarmo, \& Kurniawan, 2012).

Ket :

$$
\text { BEP Produksi } Y=\frac{F C}{P-A V C}
$$

$\mathrm{Y}=$ Jumlah Produksi $(\mathrm{Kg})$

FC = Biaya Tetap Produksi (Rp)

$\mathrm{P}=$ Harga Jual Produksi $(\mathrm{Rp} / \mathrm{Kg})$

$\mathrm{AVC}=$ Biaya Variabel Produksi $(\mathrm{Rp})$

\section{HASIL DAN PEMBAHASAN}

Secara Geografis Kabupaten Aceh Besar terletak antara $5^{\circ}, 2^{\prime}-5^{\circ}, 8^{\prime}$ Lintang Utara dan $95^{\circ} 80^{\prime}-95^{\circ}, 88^{\prime}$ Bujur Timur dengan luas wilayah $2.974,12 \mathrm{Km}^{2}$ dan panjang pantai $195 \mathrm{Km}^{2}$. Dengan batasbatas wilayah sebagai berikut : sebelah Utara berbatasan dengan Selat Malaka, sebelah selatan berbatasan dengan Kabupaten Aceh Jaya, sebelah barat berbatasan dengan Kabupaten Pidie, dan sebelah timur berbatasan dengan Samudera India. 
Berdasarkan karakteristik tanah dan iklim Kabupaten Aceh Besar sangat cocok untuk pengembangan pertanian. Jumlah Penduduk Kabupaten Aceh Besar adalah 425.528 jiwa dan 67,50\% mata pencaharian penduduknya adalah sebagai petani.

Dari hasil penelitian menunjukkan sebaran karakteristik responden di daerah penelitian yang terdiri umur, tingkat pendidikan, dan luas lahan petani. Menurut BPS (2007), tingkatan umur dapat digolongkan sebagai berikut : muda ( $<39$ tahun), menengah (39-51 tahun), dan tua (> 51 tahun). Berdasarkan data dapat diketahui bahwa umur petani yang direhab jaringan irigasi tersiernya umumnya oleh golongan umur kategori menengah (39-51 tahun) berjumlah 46 orang atau 56,09\%. Salah satu indikator yang menentukan produktivitas kerja untuk pengembangan suatu usaha ialah tingkat umur, dimana umur petani yang lebih muda dianggap lebih produktif, kuat bekerja dan lebih mudah dalam menerima inovasi baru bila dibandingkan dengan tenaga kerja yang sudah memiliki usia relatif tua (Soekartawi, 1995). Tingginya petani golongan umur kategori dewasa di Kabupaten Aceh Besar sangat berpengaruh langsung terhadap produktivitas kerja seseorang.

Menurut hasil penelitian menunjukkan bahwa petani tergolong produktif dengan umur rata-rata 42,2 tahun. Hal ini menunjukkan bahwa fisik petani sangat mendukung untuk menjalankan berbagai aktivitas dalam budi daya padi, sehingga kontribusi tenaga kerja keluarga banyak tercurah, tetapi tidak ada regenerasi petan.

Pendidikan merupakan salah satu indikator untuk menentukan kualitas sumberdaya manusia karena tingkat pendidikan akan berpengaruh terhadap tingkat penyerapan ilmu pengetahuan dan teknologi dalam pengembangan usahatani padi. Tingkatan pendidikan menurut Undang-Undang No 20 tahun 2003 digolongkan menjadi : rendah (tidak sekolah, tidak tamat SD, tamat SD), sedang (tamat SLTP atau sederajat), dan tinggi (tamat SLTA, akademi, atau perguruan tinggi). Responden pada tempat atau lokasi penelitian ini sebahagian besar telah mendapatkan pendidikan formal, mulai dari tingkat sekolah dasar (SD), Sekolah Menengah Pertama ((SMP), Sekolah Menengah Atas (SMA) hingga tingkat Perguruan Tinggi (PT). Tingkat pendidikan petani yang mendapatkan bantuan rehab jaringan irigasi tersier di Kabupaten Aceh Besar termasuk kategori tinggi yaitu sejumlah 46 orang atau $56,09 \%$.

Lahan merupakan faktor utama dalam usahatani dimana luas lahan sangat menentukan keberhasilan dalam usahatani. Salah satu faktor produksi atau tempat dihasilkannya produk pertanian yang memberikan sumbangan cukup besar untuk usahatani ialah lahan (Suratiyah, 2006). (Sajogyo, 1977) mengelompokkan petani di Jawa ke dalam tiga kategori menurut kepemilikan luas lahan dan diadopsi juga oleh BPS yaitu : petani skala kecil dengan luas lahan usahatani $<0,5$ ha, skala menengah dengan luas lahan usahatani 0,5-1,0 ha, dan skala luas lahan usahatani $>1,0$ ha. Untuk Kabupaten Aceh Besar skala lahannya tergolong skala kecil karena rata-rata petani memiliki luas lahan $<0,5$ ha atau 51,22 $\%$.

\section{Pola Tanam}

Pola tanam yang diterapkan didaerah penelitian yaitu kabupaten Aceh Besar sebelum dilakukan rehabilitasi jaringan irigasi tersier yaitu 
padi-padi dengan penanaman dua kali dalam satu tahun. Penanaman dilakukan secara konvensional belum mengadopsi teknologi baik dari segi pengolahan tanah, penanaman dan pemanenan. Pemilihan benih padi yang ditanam hanya belum bervariasi dikarenakan karena keterbatasan air sehingga petani memilih satu jenih benih padi saja yang dianggap lebih tahan terhadap kekurangan air dan serangan hama sehingga mengurangi resiko kegagalan panen.

Pola tanam yang diterapkan sesudah dilakukan rehabilitasi jaringan irigasi tersier masih padi-padi dengan penanaman dua kali dalam satu tahun tetapi sudah mengadopsi teknologi baik dalam pengolahan tanah, penanaman dan pemanenan serta dalam pemilihan benih padi yang digunakan sudah bervariasi. Hal ini dikarenakan sudah tercukupinya air pada masa penanaman sehingga benih padi yang ditanam dapat tumbuh dengan optimal dan produksi juga meningkat. Keterbatasan air merupakan alasan yang menyebabkan harus dilakukan pengaturan pola tanam dalam 1 tahun (Agushinta, dkk 2011). Petani tradisional umumnya menanam padi hanya berdasarkan pengalaman. Karena pengetahuan yang terbatas itulah satu jenis padi sering ditanam terus menerus dalam satu lahan.

\section{Analisa Produksi Padi dan Pendapatan Petani sebelum dan sesudah Rehabilitasi Jaringan Irigasi Tersier}

Tabel. 2 Hasil Produksi dan Pendapatan Usahatani Padi Sawah Sebelum dan Sesudah Rehabilitasi Jaringan Irigasi Tersier

\begin{tabular}{lrr}
\hline Uraian & $\begin{array}{c}\text { Sebelum Rehabilitasi } \\
\text { Jaringan Irigasi }\end{array}$ & \multicolumn{2}{c}{$\begin{array}{c}\text { Sesudah Rehabilitasi Jaringan } \\
\text { Irigasi }\end{array}$} \\
\hline Produksi $(\mathrm{Kg} / \mathrm{Ha})$ & 3.783 & 7.331 \\
\hline Penerimaan $(\mathrm{Rp} / \mathrm{Ha})$ & 16.888 .056 & 33.786 .389 \\
\hline Biaya Produksi $(\mathrm{Rp} / \mathrm{Ha})$ & 5.408 .418 & 4.403 .078 \\
\hline Pendapatan $(\mathrm{Rp} / \mathrm{Ha})$ & 11.479 .638 & 29.383 .311 \\
\hline
\end{tabular}

Sumber : Data Primer (Diolah), 2018

Dari Tabel 2 dapat dilihat perubahan hasil produksi petani sebelum dan sesudah program rehabilitasi jaringan irigasi tersier, pada tabel 1 perubahan kearah positif terlihat dari semakin meningkatnya hasil produksi gabah petani dari $3.783 \mathrm{Kg} / \mathrm{Ha}$ menjadi 7.331 $\mathrm{Kg} / \mathrm{Ha}$, dengan sebaran luas lahan tetap yakni $36 \mathrm{Ha}$, dan jumlah petani sebagai responden tetap yaitu 82. Dengan meningkatnya produksi gabah petani sejalan dengan bertambahnya penerimaan petani dari $\mathrm{Rp}$ 16.888.056/Ha sebelum rehap menjadi Rp. 33.786.389/Ha setelah rehap diwilayah tersebut. Selain itu pendapatan bersih petani juga berubah dari Rp. 11.479.638/Ha menjadi Rp. 29.383.311 setelah rehap. Penambahan pendapatan setelah program rehabilitasi jaringan irigasi tersier petani dikarenakan penggunaan input produksi dalam budidaya menurun, seperti penggunaan pestisida dan obat-obatan lainnya disebabkan karena tercukupinya pengairan untuk lahan sawah. Dengan asumsi apabila penggunaan faktor produksi berupa luas lahan, jumlah benih, jumlah pupuk dan jumlah tenaga kerja tetap maka fungsi rehabilitasi berjalan dengan baik. Hasil penelitian Mahananto,dkk (2009) mengungkapkan bahwa peningkatan produksi padi sawah sangat dipengaruhi oleh jumlah pupuk, luas lahan garapan, jumlah tenaga kerja 
efektif, jumlah obat-obatan dan sistem irigasi.

\section{Analisa Uji t}

Untuk melihat perbedaan hasil produksi dan pendapatan petani padi sawah sebelum dan sesudah rehabilitasi jaringan irigasi tersier digunakan metode uji t yang hasilnya sebagai berikut:

Tabel 3. Rata-rata Perbedaan Pendapatan sebelum dan sesudah rehabilitasi jaringan irigasi tersier

\begin{tabular}{llc}
\hline No & Uraian & $\begin{array}{l}\text { Pendapatan } \\
\text { Bersih }(\mathrm{Rp} / \mathrm{Ha})\end{array}$ \\
\hline 1 & Pendapatan Sesudah Rehabilitasi & 12.507 .795 \\
\hline 2 & Pendapatan Sebelum Rehabilitasi & \\
\hline & Uji t $\mathrm{t}_{\text {cari }}=11,47$ & $\mathrm{t}_{\text {tabel }}=1,66$ \\
\hline
\end{tabular}

Sumber : Data Primer (Diolah), 2018

Tabel 4. Rata-rata Perbedaan Produksi sebelum dan sesudah rehabilitasi jaringan irigasi tersier

\begin{tabular}{llcc}
\hline No & Uraian & $\begin{array}{l}\text { Produksi } \\
(\mathrm{Kg} / \mathrm{Ha})\end{array}$ \\
\hline 1 & Produksi Sesudah Rehabilitasi & 3.218 \\
\hline 2 & Produksi Sebelum Rehabilitasi & & 1.661 \\
\hline & Uji $_{\text {cari }}=9,99$ & $\mathrm{t}_{\text {tabel }}=1,66$ & \\
\hline
\end{tabular}

Sumber : Data Primer (Diolah), 2018

Dari Tabel 3 dan tabel 4 dapat dilihat bahwa hasil dari pengujian hipotesis pada $\alpha=0,05$ yang diperoleh nilai t-hitung 6,10 lebih besar dari t-tabel yaitu 1,66 untuk pendapatan petani dan nilai t-hitung 9,99 lebih besar dari t-tabel yaitu 1,66 untuk produksi petani maka $\mathrm{H}_{0}$ tidak diterima dan $\mathrm{H}_{\mathrm{a}}$ diterima. Sehingga dapat disimpulkan bahwa adanya perbedaan yang nyata pada produksi padi sebelum dan sesudah dilakukannya rehabilitasi jaringan irigasi tersier. Walaupun ditinjau dari sisi pendapatan petani sebelum rehabilitasi jaringan irigasi tersier pendapatan petani menunjukkan tren positif namun jika ditinjau dari penggunaan input produksi sangat tinggi dibandingkan setelah adanya program rehabilitasi jaringan irigasi tersier.

Ketersediaan air yang cukup bagi tanaman sangat berpengaruh pada peningkatan produktivitas karena bertambah suburnya tanah, kurangnya serangan hama dan penyakit serta penanaman padi yang tidak tergantung lagi hanya pada musim hujan. Peningkatan produktivitas padi di Kabupaten Aceh Besar disebabkan karena beberapa hal : adanya jaringan irigasi mendorong petani untuk menggunakan input produksi seperti pupuk dan pestisida dengan lebih baik. Adanya jaringan irigasi juga mendorong petani untuk menerapkan teknik budidaya dengan lebih baik. Hal ini menyebabkan peningkatan produktivitas rata-rata petani. Walaupun tidak terjadi peningkatan produktivitas rata-rata secara keseluruhan, adanya jaringan irigasi memungkinan petani untuk meningkatkan intensitas pertanaman. Irigasi memungkinkan petani dapat menanam sepanjang tahun. Peningkatan 
intensitas pertanaman akan meningkatkan produksi total per tahun.

\section{Analisa R/C Ratio}

Dari hasil observasi dilapangan dan analisis data, peningkatan produksi padi dapat diasumsikan sebagai ukuran peningkatan pendapatan petani. Jika secara umum pendapatan petani dalam suatu wilayah mengalami peningkatan maka perekonomian wilayah tersebut semakin membaik. Berdasarkan hasil jawaban 82 responden menyatakan produksi padi mereka mengalami peningkatan setelah adanya program rehabilitasi jaringan irigasi tersier.

Peningkatan produksi padi tersebut dengan rincian sebesar 82 responden atau $93 \%$ menyatakan produksi padi mereka meningkat $1 \%$ s.d $25 \%$, mayoritas pendapatan responden mengalami peningkatan setelah jaringan irigasi tersier disekitar lahan mereka direhap, rehab jaringan irigasi tersier telah membawa pengaruh terhadap peningkatan produksi padi di Kabupaten Aceh Besar.

Peningkatan produksi petani seiring dengan perubahan pendapatan setelah adanya rehab, walaupun sebelum dilakukannya rehab usahatani petani sudah layak, namun dibanding setelah adanya rehab pendapatan mereka semakin meningkat, berikut analisis R/C rasio untuk usahatani padi disekitar area rehabilitasi jaringan irigasi tersier.

Tabel. 5. Analisis R/C Rasio terhadap Pendapatan Petani Sebelum dan Setelah Rehabilitasi Jaringan Tersier

\begin{tabular}{lccc}
\hline No & & Sebelum (2015) & Sesudah (2017) \\
\hline 1 & Pendapatan Total (Rp) & 381.106 .900 & 1.025 .639 .200 \\
\hline 2 & Biaya Total (Rp) & 226.863 .100 & 190.670 .800 \\
\hline & R/C Ratio & 2 & 5,38 \\
\hline
\end{tabular}

Sumber : Data diolah

Dari tabel 5 terlihat $\mathrm{R} / \mathrm{C}$ rasio terhadap pendapatan petani sebelum dan sesudah adanya rehab $\mathrm{R} / \mathrm{C}$ rasio samasama menunjukkan lebih besar dari 1 , dengan artian usahatani layak dijalan, namun sesudah adanya rehab

Tabel. 6. Analisis Break Even Point (BEP) Petani Sebelum dan Setelah Rehabilitasi Jaringan Tersier

\begin{tabular}{lrr}
\hline Uraian & Tahun 2015 Sebelum BEP & Tahun 2017 Setelah BEP \\
\hline Jumlah Biaya Produksi & 226.863 .100 & 190.670 .800 \\
\hline Jumlah Penerimaan & 607.970 .000 & 1.216 .310 .000 \\
\hline Pendapatan Total & 381.106 .900 & 1.025 .639 .200 \\
\hline Break Even Point & $22.465 \mathrm{Kg}$ & $8.263 \mathrm{Kg}$ \\
\hline
\end{tabular}

Sumber : Data diolah

Dari hasil analisis Break event point (BEP) untuk 82 responden dengan luas lahan 36 Ha menunjukkan tahun 2015 sebelum kegiatan rehabilitasi jaringan pendapatan petani margin labanya lebih besar yakni dari 2 menjadi 5,38.

\section{BEP Rehabilitasi Jaringan Irigasi Tersier}


untuk berada pada titik impas harus menghasilkan produksi atau break even point sebesar $8.263 \mathrm{~kg}$. Apabila penerimaan petani kurang dari Break even point maka program rehabilitasi jaringan irigasi tersier tidak membawa dampak yang positif untuk petani disekitar area program. Dari hasil Break even point sesudah rehabilitasi jaringan irigasi tersier terdapat selisih $14.202 \mathrm{~kg}$ dimana nilai untuk mencapai BEP sesudah rehabilitasi lebih rendah.

Dengan semakin baiknya sarana penunjang untuk mencukupi ketersediaan air untuk usahatani padi maka penggunaan input produksi semakin rendah dan hasil produksi padi dan pendapatan petani makin meningkat pula. Dengan hasil tersebut dapat disimpulkan bahwa program rehabilitasi jaringan irigasi tersier memberikan dampak positif bagi petani. Hal ini sesuai dengan pendapat (Suharto et al., 2012) yang menyatakan bahwa proyek pemeliharaan irigasi cukup berpengaruh terhadap hasil produksi pertanian di desa Kademangan dimana perubahan banyaknya debit air pada jaringan irigasi memberikan masukan yang cukup positif terhadap kelancaran proses produksi pertanian.

\section{KESIMPULAN}

Rehabilitasi jaringan irigasi tersier tidak berdampak terhadap perubahan Pola tanam tetap 2 kali dalam setahun yaitu MT I (Musim hujan) dan MT II (Musim Gadu) tetapi dalam hal pengolahan tanah, penanaman dan pemanenan sesudah rehab sudah mengadopsi teknologi seperti penanaman padi dengan sistem SRI dan legowo super dan pemanenan dengan menggunakan Combine Harvester.

Rehabilitasi jaringan irigasi tersier berdampak terhadap peningkatan produksi padi sawah dari 3.783
$\mathrm{Kg} / \mathrm{Ha} / \mathrm{MT}$ menjadi $7.331 \mathrm{Kg} / \mathrm{Ha} / \mathrm{MT}$ dan peningkatan pendapatan petani dari Rp. $\quad 11.479 .638 / \mathrm{Ha} / \mathrm{MT}$ menjadi 29.383.311/Ha/MT dan secara ekonomis sebelum dan sesudah adanya rehabilitasi jaringan irigasi tersier $\mathrm{R} / \mathrm{C}$ rasio samasama menunjukkan lebih besar dari 1, dengan artian usahatani layak dijalankan, namun sesudah adanya rehabilitasi jaringan irigasi tersier pendapatan petani margin labanya lebih besar yakni dari 2 menjadi 5,38.

Dari hasil analisis Break event point (BEP) untuk 82 responden dengan luas lahan $36 \mathrm{Ha}$ menunjukkan tahun 2015 sebelum kegiatan rehabilitasi jaringan irigasi tersier untuk berada pada titik impas petani harus menghasilkan produksi sebesar $22.465 \mathrm{~kg}$. Sedangkan setelah rehab pada tahun 2017 petani untuk berada pada titik impas harus menghasilkan produksi sebesar 8.263 kg. Dari hasil Break even point sesudah rehab terdapat selisih $14.202 \mathrm{~kg}$ dimana nilai untuk mencapai BEP sesudah rehabilitasi lebih rendah. Apabila Penerimaan Petani kurang dari Break even point maka program rehabilitasi jaringan irigasi tersier tidak membawa dampak yang positif untuk petani disekitar area program. Dari hasil penelitian menunjukkan bahwa dengan adanya rehabilitasi jaringan irigasi tersier memberikan dampak yang positif bagi petani dimana semakin baiknya jaringan irigasi maka penggunaan input produksi semakin rendah dan hasil produksi padi dan pendapatan petani makin meningkat pula.

\section{DAFTAR PUSTAKA}

Agushinta, D., Suhendra, A., Madenda, S., \& Suryadi, H. S. (2011). Face Component Extraction Using Segmentation Method on Face Recognition System. Journal of Emerging Trends in Computing 
and Information Sciences, 2(0), 2.

Mahananto, Sutrisno, S., \& Ananda, C. F. (2009). Faktor-Faktor Yang Mempengaruhi Produksi Padi Studi Kasus Di Kecamatan Nogosari, Boyolali, Jawa Tengah. Wacana, Jurnal Sosial Dan Humaniora, 12(1), 179-191.

Pasandaran, E. (2016). Pengelolaan Infrastruktur Irigasi Dalam Kerangka Ketahanan Pangan Nasional. Analisis Kebijakan Pertanian, 5(2), 126-149.

Sajogyo, P. (1977). The Integration of Rural Women in National Development in Indonesia. Home economics and Social Programmes Service, Human Resources, Institutions and Agrarian Reform Division, Food and Agriculture Organization of the United Nations.
Sidharta, S. K. (1997). Irigasi dan Bangunan Air. Jakarta: Guna Darma.

Simatupang, P., \& Rusastra, I. W. (2004). Kebijakan Pembangunan Sistem Agribisnis Padi. Ekonomi Padi dan Beras Indonesia.

Soekartawi. (1995). Analisis Usahatani. Universitas Indonesia.

Suharto, B., Wirosoedarmo, R., \& Kurniawan, A. (2012). Financial Evaluation Study on Maintenance Project of Irrigation Facilities (Case Study on Sumber Kedung Kandang Irrigation Sector, Kademangan Village, Gondang Legi, Malang). Jurnal Teknologi Pertanian, 2(1).

Suratiyah, K. (2006). Ilmu usahatani. Penebar Swadaya Grup. 